\title{
Diopside Glass-Ceramics for Dental and Biomedical Applications
}

\author{
Jamila Almuhamadi ${ }^{1, a^{*}}$, Natalia Karpukhina ${ }^{2, b}$ and Mike Cattell ${ }^{1, a}$ \\ ${ }^{1}$ Centre for Adult Oral Health, Barts and The London School of Medicine and Dentistry, Queen \\ Mary University of London, Turner Street, Whitechapel, London E1 2AD, UK \\ ${ }^{2}$ Unit of Dental Physical Sciences, Barts and The London School of Medicine and Dentistry, Queen \\ Mary University of London, Mile End Road, London, E1 4NS, UK \\ a*j.m.a.almuhamadi@qmul.ac.uk, bn.karpukhina@qmul.ac.uk, am.cattell@qmul.ac.uk
}

Keywords: Glass-ceramics, Crystallisation, Diopside, Solid solution, TEC, NMR, SEM.

\begin{abstract}
A series of glass compositions with varying equimolar amounts of $\mathrm{Na}_{2} \mathrm{O}: \mathrm{Al}_{2} \mathrm{O}_{3}$ were designed using Appen factor. High purity batch reagents were ball milled for $30 \mathrm{~min}$ and transferred to $\mathrm{Pt} / \mathrm{Rh}$ crucible and melted in an electric furnace (EHF1700, Lenton, UK) at high temperatures then held for $90 \mathrm{~min}$. The molten glass was poured into a graphite mould, annealed at $50^{\circ} \mathrm{C}$ below glass transition temperature for $1 \mathrm{~h}$ and the remaining glass was quenched into cold water. Glass frits were crushed and ball milled into powders with different particle sizes. Glass powders with a control particle size $(\mathrm{PS}<125 \mu \mathrm{m})$ were heat-treated via two-step heat treatment cycles and air quenched. Experimental glasses and glass-ceramics were characterised using X-Ray Diffraction (XRD), Dilatometry, Scanning Electron Microscopy (SEM) and solid state Nuclear Magnetic Resonance (NMR).
\end{abstract}

Introduction

The faliure of most dental veneering ceramics on zirconia (Y-TZP) restorations due to brittle fracture (chipping) continues to be a problem [1]. A key reason for such a failure is reported to be a mismatch in thermal expansion coefficient (TEC) between framework and veneer resulting in an excessive tensile stress that is generated in the ceramic veneer during cooling [2]. Rogers et al [3] has suggested that compositions which crystallise to form solid solutions are capable of controlling properties of the produced material among these to be mentioned; thermal, chemical, physical and mechanical properties. Diopside $\left(\mathrm{Di}, \mathrm{CaMgSi}_{2} \mathrm{O}_{6}\right)$ is a member of clinopyroxene mineral family that possess a single chain silicate structure and crystallises to form a solid solution with other cations available for substitution for calcium and magnesium. Recently the solid solution that occurs via a coupled substitution between $\left(\mathrm{Ca}^{+2} / \mathrm{Mg}^{+2}\right)$ and $\left(\mathrm{Na}^{+} / \mathrm{Al}^{+3}\right)$ forming $\mathrm{C} 2 / \mathrm{C}$ monoclinic lattice have been reported [4]. Many researches have emphasised the importance of diopside and its potential applications in biomedicine and dentistry [5-8]. Diopside is a bioactive material and has been proposed for use in bone surgery due to its high bending (300Mpa) and compressive strength (1861 Mpa) which are stonger than human cortical bone [5]. It has been shown that diopside has no general toxicity in cell cultures, forms a uniform junction with newly grown bone in vivo and aids bone regeneration [6,7]. Diopside has also been documented to be capable of press-forming at 850 ${ }^{\circ} \mathrm{C}$ which resulted in formation of desired shapes [8].

The purpose of this study was to produce a new glass-ceramics based on $\mathrm{CaMgSi}_{2} \mathrm{O}_{6}-\mathrm{NaAlSi}_{2} \mathrm{O}_{6}$ binary system that is thermally compatible with zirconia (Y-TZP) and to overcome the chipping problem of dental restorations. 


\section{Experimental methods}

\section{Glass Synthesis.}

Glass batches with compositions 50-61.54 $\mathrm{SiO}_{2}, 0-11.54 \mathrm{Al}_{2} \mathrm{O}_{3}, 25-7.69 \mathrm{CaO}, 0-11.54 \mathrm{Na}_{2} \mathrm{O}$ and 25-7.69 $\mathrm{MgO}$ (mol\%) were ball milled for 30 mins with alumina grinding media $(12 \times 26.5 \mathrm{~mm}$ diameter) and heated in an electric furnace (EHF1700, Lenton, UK) at $50^{\circ} \mathrm{C} / \mathrm{min}$ up to $1450-1600^{\circ} \mathrm{C}$ (90 mins hold), poured, crushed, ball milled and re-homogenised at the same temperatures. Finally, the molten glass was poured into graphite mould and annealed at $50^{\circ} \mathrm{C}$ below glass transition temperature (Tg) for $1 \mathrm{~h}$ and the remaining was rapidly quenched into cold water to avoid crystallisation. Glass frits were ground and sieved to obtain powders with different particle sizes (PS $<45 \mu \mathrm{m}$ and $\mathrm{PS}<125 \mu \mathrm{m}$ ).

\section{Diffrential Dilatometry.}

Glass cylinders obtained from the mold were cut to a cross section with dimensions $(25 \mathrm{~mm} \times 6$ $\mathrm{mm} \times 6 \mathrm{~mm}^{3}$ ) using a plate saw (Struers Accutom 2, Struers Ltd, Glasgow, UK) under water lubrication. Glass samples were finished to flat surfaces on wet silicon carbide grinding papers. A calibration run was carried out by using a standard alumina rod (polycrystalline $\mathrm{Al}_{2} \mathrm{O}_{3}$ dilatometer standard, no: 6.219.1-92.2.00, Netzsch Instrument, Selb, Germany), heated between $25^{\circ} \mathrm{C}$ and $1200^{\circ} \mathrm{C}$ at $3^{\circ} \mathrm{C} / \mathrm{min}$ before the experimental measurements. The thermal expansion coefficient (TEC) of the glass specimens was measured using a differential dilatometer (DIL 402PC, Netzsch Instrument, Germany) in a temperature range $\left(25^{\circ} \mathrm{C}-1200^{\circ} \mathrm{C}\right)$ and at a heating rate of $3^{\circ} \mathrm{C} / \mathrm{min}$ under nitrogen gas atmosphere. Softening point protection was applied during measurement. The TEC of the glass samples were measured over a temperature range $100-400^{\circ} \mathrm{C}$ using Thermal Analysis Software, (Netzsch Proteous, ver. 4.8.2, 2006, Netzsch Instrument, Germany). The glass transition (Tg) temperature and dilatometric softening point (Dsp) were also obtained. The error in the Tg and Dsp was $\pm 5^{\circ} \mathrm{C}$.

\section{Crystallisation Studies.}

Glass powder samples $(3 \mathrm{~g}$, PS $<125 \mu \mathrm{m}$ ) were mixed with $0.9 \mathrm{ml}$ of modeling liquid (Classic modelling liquid, CH.B:24066, Vita-Zahnfabrik, Lichtenstein, Germany) and compacted in a steel mould with plunger under 1 bar pressure for $1 \mathrm{~min}$. The powder compacts were placed on platinum foils and heat treated in an electric furnace (UAF 16/10, Lenton, Hope Valley, UK) from $25^{\circ} \mathrm{C}$ at a rate of $20^{\circ} \mathrm{C} / \mathrm{min}$ up to various nucleation temperatures, $100 \mathrm{Di}-0 \mathrm{Jd}: 762{ }^{\circ} \mathrm{C}, 85 \mathrm{Di}-15 \mathrm{Jd}: 732{ }^{\circ} \mathrm{C}$, 75Di-25Jd: $727{ }^{\circ} \mathrm{C}$, 50Di-50Jd: $710{ }^{\circ} \mathrm{C}$ and 25Di-75Jd: $706{ }^{\circ} \mathrm{C}$, held for $1 \mathrm{~h}$ and ramped up to the crystal growth temperatures $100 \mathrm{Di}-0 \mathrm{Jd}$ : $929{ }^{\circ} \mathrm{C}$, 85Di-15Jd: $933{ }^{\circ} \mathrm{C}$, 75Di-25Jd: $944{ }^{\circ} \mathrm{C}$, 50Di-50Jd: $984^{\circ} \mathrm{C}$ and 25Di-75Jd: $1006^{\circ} \mathrm{C}$, held for $1 \mathrm{~h}$ and then air quenched.

\section{X-Ray Diffraction.}

Glass and glass-ceramic powders were analysed using X'Pert Pro X-ray diffractometer (Panalytical, B.V., Almelo, and The Netherlands). Bragg-Brentano flat plate geometry and $\mathrm{Cu} \mathrm{K \alpha}$ radiation $(\lambda 1=1.54059 \AA$ and $\lambda=1.54442 \AA)$ was used. Data was collected from $5^{\circ}$ to $120^{\circ}(2 \theta)$, with the $X^{\prime}$ Celerator in continuous mode giving data equivalent to a count time of $200 \mathrm{~s}$ and an interval of $0.0334^{\circ} 2 \theta$ on a normal diffractometer. Phase analysis was carried out using the PANalytical X'Pert high score plus software (ICDD: PDF-4 database). The structural model of diopside (ICDD: 04-005-9771) was used for identifying the phase .

\section{Nuclear Magnetic Resonance-Magic Angle Spinning.}

Fine ground powder of glass/glass-ceramic samples were packed into $4 \mathrm{~mm}$ zirconia rotors. The ${ }^{27}$ Al NMR experimentation was carried out using a $600 \mathrm{MHz}$ NMR spectrometer (DRX-600 Bruker Avance, Germany) with MAS at a spinning rate of 15-20 kHz. Magnetic field of 11.4T corresponding to a resonance frequency of $156.3 \mathrm{MHz}$ was applied for ${ }^{27} \mathrm{Al}$. The recycle delay was 
chosen to be $0.5 \mathrm{~s}$ throughout, so that spectra were completely relaxed. The ${ }^{27} \mathrm{Al}$ chemical shift was referenced to $0 \mathrm{ppm}$ frequency of the corresponding signals in $1 \mathrm{M} \mathrm{Al}\left(\mathrm{NO}_{3}\right)_{3}$ aqueous solution. Spectra analyses were performed using (Bruker Topspin 2.1 software).

\section{Scanning Electron Microscopy.}

Glass-ceramics specimens were embedded in epoxy resin, polished using $0.3 \mu \mathrm{m}$ alumina micropolish (Buehler, USA) and ultrasonically cleaned for 10mins. Glass-ceramics specimens were etched with $2 \%$ hydrofluoric acid (HF) for $60 \mathrm{~s}$, water rinsed and cleaned with ethanol for $30 \mathrm{~s}$. Specimens were gold coated using an automatic sputter coater (Agar Scientific Ltd, Stansted, 108 A, England) and viewed under secondary electron imaging with a field emission scanning electron microscope (FEI Inspect F, Oxford Instruments, Oxfordshire, UK) using an accelerating voltage of $10 \mathrm{kV}$ together with $10 \mathrm{~mm}$ working distance and 3.5 spot size.

\section{Results and Discussion.}

\section{Differential Dilatometry Results.}

The results from the differential dilatometry are presented in Table 1. The codes for the glass compositions are referred to the pseudobinary stoichiometry of $\mathrm{CaMgSi}_{2} \mathrm{O}_{6}(\mathrm{Di})-\mathrm{NaAlSi}_{2} \mathrm{O}_{6}(\mathrm{Jd})$. The glass transition temperatures were gradually decreased from 732 to $676{ }^{\circ} \mathrm{C}$ in all glass formulations. Similar observations were reported by Jindal et al.[9]. The dilatometric softening point temperatures Dsp were also decreased from 778 to $723{ }^{\circ} \mathrm{C}$ up to 50Di-50Jd while increased again with further increasing of Di-Jd ratio in the glass (Table 1). The reduction in glass transition temperatures and dilatometric softening point could be related to the replacement/substitution of $\mathrm{Ca}^{+2}$ in (Di) by $\mathrm{Na}^{+}$in $(\mathrm{Jd})$. This substitution causes breakdown in the glass netwrok due to the lower fileld strengh of $\mathrm{Na}^{+}(0.19)$ compared to that of $\mathrm{Ca}^{+2}(0.35)$. This means that $\mathrm{Na}^{+}$will have lower attraction effect on the surronding oxygens than $\mathrm{Ca}^{+2}$.

The thermal expansion coefficient of glasses was intially increased to $8.55 \times 10^{-6} / \mathrm{K}$ with increasing $\mathrm{Jd}$ ratio up to $15 \%$. However, this value was decreased when $25 \% \mathrm{Jd}$ was added and decreased to minmum, $8.11 \times 10^{-6} / \mathrm{K}$ with the highest addition of $\mathrm{Jd}$ ratio, $75 \%$. The same behaviour was seen in the glass-ceramics where the highest value, $9.22 \times 10^{-6} / \mathrm{K}$ was recorded for the lowest $\mathrm{Jd}$ glass and decreased with increasing $\mathrm{Jd}$ ratio at the expense of Di. The intial increases in TEC value when $15 \%$ of $\mathrm{Jd}$ ratio was added may be attributed to the intrdodution of $\mathrm{Na}_{2} \mathrm{O}$ into the glass, thus $\mathrm{Na}^{+}$ replaces $\mathrm{Ca}^{+2}$ in the glass structure, disrupts the network and lead to increases in the TEC. On the other hand, the reduction in the TEC value as Jd content increased might be due to the increase of $\mathrm{Al}_{2} \mathrm{O}_{3}$ in the glass. It has been suggested [10] that increase of $\mathrm{Al}$ in the glass can lead to an isomorphous substitution of $\mathrm{Al}$ for $\mathrm{Si}$ in the glass network. Thus, Al might be incorporated in the network as $\mathrm{Q}^{4}$ species, which in turn enhances/increases the ionic crosslinking and polimerises the glass structure.

Table 1. Thermal properties results of experimental glasses and gass-ceramics. The codes for the glass compositions are referred to the pseudobinary stoichiometry of $\mathrm{CaMgSi}_{2} \mathrm{O}_{6}$ (Di) - $\mathrm{NaAlSi}_{2} \mathrm{O}_{6}$

(Jd).

\begin{tabular}{|c|c|c|c|c|}
\hline code & $\begin{array}{c}\mathrm{Tg} \\
\left({ }^{\circ} \mathrm{C}\right)\end{array}$ & Dsp $\left({ }^{\circ} \mathrm{C}\right)$ & $\begin{array}{c}\text { TEC-Glasses } \\
\left(\times 10^{-6} / \mathrm{K}\right)\end{array}$ & $\begin{array}{c}\text { TEC-Glass-ceramics } \\
\left(\times 10^{-6} / \mathrm{K}\right)\end{array}$ \\
\hline 100Di-0Jd & 732 & 778 & 8.29 & 9.12 \\
\hline 85Di-15Jd & 704 & 748 & 8.55 & 9.22 \\
\hline 75Di-25Jd & 697 & 749 & 8.14 & 9.11 \\
\hline 50Di-50Jd & 680 & 723 & 8.35 & 8.65 \\
\hline 25Di-75Jd & 676 & 737 & 8.11 & 8.66 \\
\hline
\end{tabular}




\section{X-Ray Diffaraction Results.}

All experimental glasses exhibited amorphous phase. The heat treated glasses after two-step heat treatments showed a presence of diopside as the major crystalline phase (Fig 1). A small peak assosiated with albite phase $\left(\mathrm{NaAlSi}_{3} \mathrm{O}_{8}\right)$ was observed in two glass-ceramic formulasions with high $\mathrm{Jd}$ content ( $50 \mathrm{Jd}$ and $75 \mathrm{Jd}$ ). There was a shift in the peak intensity with increases in $\mathrm{Jd}$ ratio. This shift might be due to the formation of diopside solid solution. This is in agreement with data reported by Abo-Mossalam et al [4] on diopside-jadeite-fluorapatite system. In his study, two crystalline phases were evident which have been identified as fluorapatite and a solid solution. This is the first time in literature where a stable solid solution was reported at atmosheric pressure. However, no crystalline peak for crystalline $\mathrm{NaAlSi}_{2} \mathrm{O}_{6}$ (jadeite) at normal pressure was noticed since jadeite is only known to be formed at high pressure ( $\geq 3 \mathrm{GPa})$.

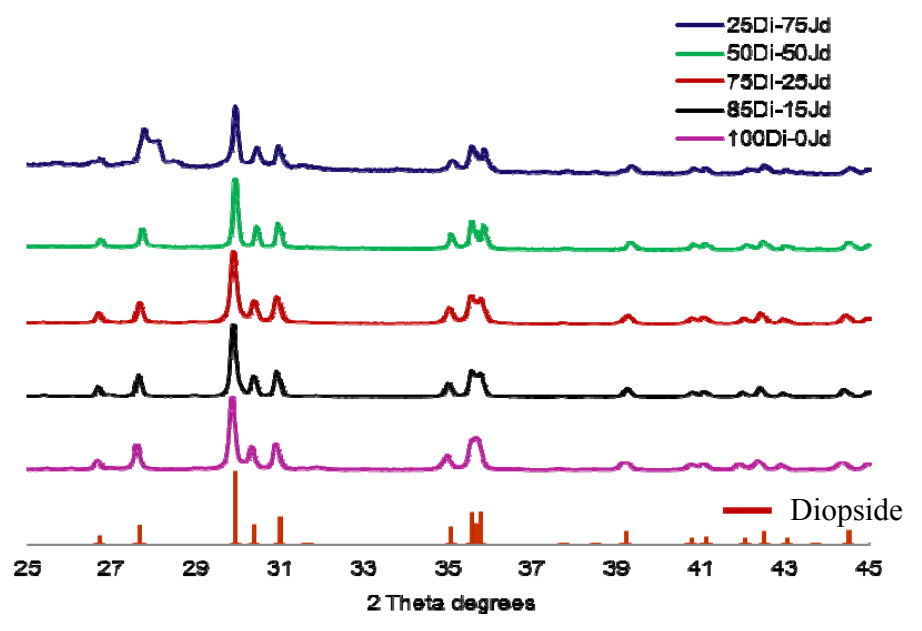

Fig 1. XRD plots of heat-treated glasses.

\section{${ }^{27}$ Al MAS-NMR results.}

The ${ }^{27}$ Al MAS-NMR spectra of the experimental glasses are plotted in Fig 2 a. The prominent peak with maxima at 56.6-57.2 $\mathrm{ppm}$ is corresponding to a four coordinated aluminium tetrahedral species, $\mathrm{Al}(\mathrm{IV})$. The $\mathrm{Al}(\mathrm{IV})$ peak appears quite broad while it narrows down with increasing $\mathrm{Na}_{2} \mathrm{O}$ and $\mathrm{Al}_{2} \mathrm{O}_{3}$ substitution. Similar finding was illustrated in previous studies $[4,11]$. A small fraction of $\mathrm{Al}(\mathrm{V})$ at $14.9-15.5 \mathrm{ppm}$ was noticed in glasses, $85 \mathrm{Di}-15 \mathrm{Jd}$ and $75 \mathrm{Di}-25 \mathrm{Jd}$. This is due to a contamination of glass powders with almunia grinding media during ball milling process. The presence of $\mathrm{Al}(\mathrm{IV})$ species in the glasses suggests that alumnium is acting as a network former in aluminosillicate glasses.

The ${ }^{27} \mathrm{Al}$ MAS-NMR spectra of heat-trated glasses are plotted in Fig $2 \mathrm{~b}$. The broad peak with maxima at 55.6-58.2ppm is corresponding to a four coordinated aluminium Al(IV) species and appears narrower compared to that presented in the glasses. A sharp crystalline peak at about $-4 \mathrm{ppm}$ corresponding to $\mathrm{Al}(\mathrm{VI})$ species is also present reflecting the formation of diopside solid solution. The solid solution presented here at ambient pressure is very similar to that found at high pressure $(-5 \mathrm{ppm})[12]$ and has characetristic of ${ }^{2} \mathrm{Q}$ silicate chain structure. This explains that $\mathrm{Al}^{+3}$ in $\mathrm{Al}(\mathrm{VI})$ acts ony as network modifier cation, charge balancing with $\mathrm{Si}^{+4}$ and maintain the electro-neutrality of the structure. A decrease in the relative intensity of $\mathrm{Al}(\mathrm{VI})$ in a solid solution was observed with increasing $\mathrm{Na}_{2} \mathrm{O}$ and $\mathrm{Al}_{2} \mathrm{O}_{3}$ substitution. The varaition in the intensity of these peaks as the composition changes can be interperated as increasing of amorphoous phase in the form of $\mathrm{Al}(\mathrm{IV})$ with increasing of aluminum content. Abo-Mosallam et al.[4] has estimated the proportion of $\mathrm{Al}(\mathrm{VI})$ into $\mathrm{Al}(\mathrm{IV})$ and $\mathrm{Al}(\mathrm{VI})$ in the solid solution from fitting NMR spectra. These authors found that the amount of $\mathrm{Al}(\mathrm{VI})$ was linearlly increased as a function of increasing the aluminum content into the system. However, this amount was limited to only $20 \%$ from the total aluminum 
concentration. This confirms that there is always a limited maxium value for the total substitution of $\mathrm{Al}^{+3} / \mathrm{Na}^{+}$for $\mathrm{Mg}^{+2} / \mathrm{Ca}^{+2}$ despite the amount of aluminum added to the compositions.
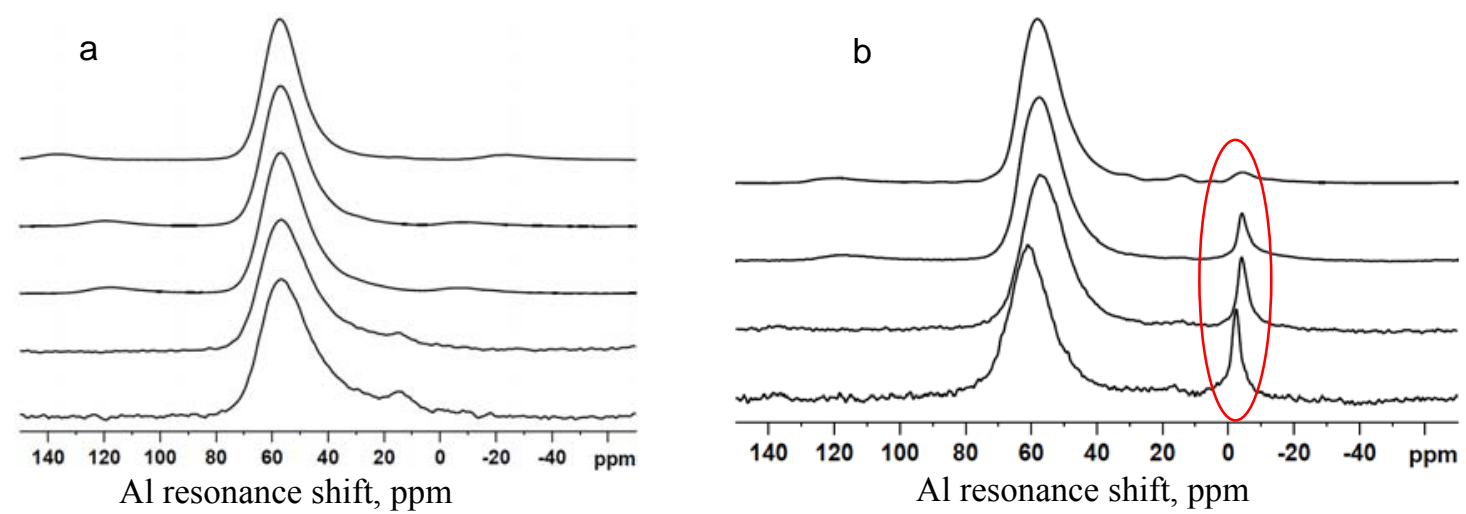

Fig 2. (a) ${ }^{27} \mathrm{Al}$ MAS-NMR spectra of glasses at $12 \mathrm{KHz}$ spining rate and (b) ${ }^{27} \mathrm{Al}$ MAS-NMR spectra of glass-ceramics at $12 \mathrm{KHz}$ spining rate.

\section{Secondary Electrom Imaging (SEI) Results.}

The SEI results of the glass-ceramics after two-step heat treatments are shown in Fig 3(a-e). The prominent crystalline phase shown here is diopside as perviously confirmed by XRD data. The glass-ceramic microstructure of pure diopside shows high crystallinity of diopside and crystal coalasence at the grain boundries with no evedince of matrix microcracking (Fig 3a). Previous study [8] has shown that after heat-treatment of the glass based on $\mathrm{CaO}-\mathrm{MgO}-\mathrm{Si}_{2} \mathrm{O}-\mathrm{TiO}_{2}-\mathrm{Ag}_{2} \mathrm{O}$ system at $900^{\circ} \mathrm{C}$, diopside crystals were grown greatly reaching more than $50 \mu \mathrm{m}$. It was also found that the quantity of diopside precipitation increased with increasing the crystallisation temperature. At $830^{\circ} \mathrm{C}$ diopside was about $3 \%, 20 \%$ at $850{ }^{\circ} \mathrm{C}$ and $80 \%$ at $900{ }^{\circ} \mathrm{C}$. Recently, Ott et al [13] has studied the growth mechanism of diopside and emphasised that diopside grows in two different layers. A large layer of homogenous growth structure are first present, this is however were subjected to an orientation change of the $c$-axes from being parallel to being perpendicular to the surface. Introducing $\mathrm{Na}_{2} \mathrm{O}$ and $\mathrm{Al}_{2} \mathrm{O}_{3}$ into the compositions produced glass-ceramics with rosette, dentritic and platelet/fibre-like diopside crystals with absence of matrix microcracking (Fig b-e). In addition, the amount of crystal phase formed was decresed with increasing Jd content as a function of crystallisation temperature. This is again supports the results mentioned above from XRD. The morphology, orientation, and size of these crystals clearly indicate that surface crystallisation took place in only one preferred orientation. This is in agreement with the results observed by Öveçoğlu et al. [14 ] where diopside crystals were reported to be grown in one preferred orientation and their lengh were in the range of $15-40 \mu \mathrm{m}$ whereas their width were about $5 \mu \mathrm{m}$. Some droplets were seen on the glass matrix background of glass-ceramics, 50Di-50Jd and 25Di-75Jd. This might be an indication for a phase separation and a presence of albite in the residual glass. This might explain the reduction of the thermal expansion coeffient of these two formulations (see above, Table 1). 

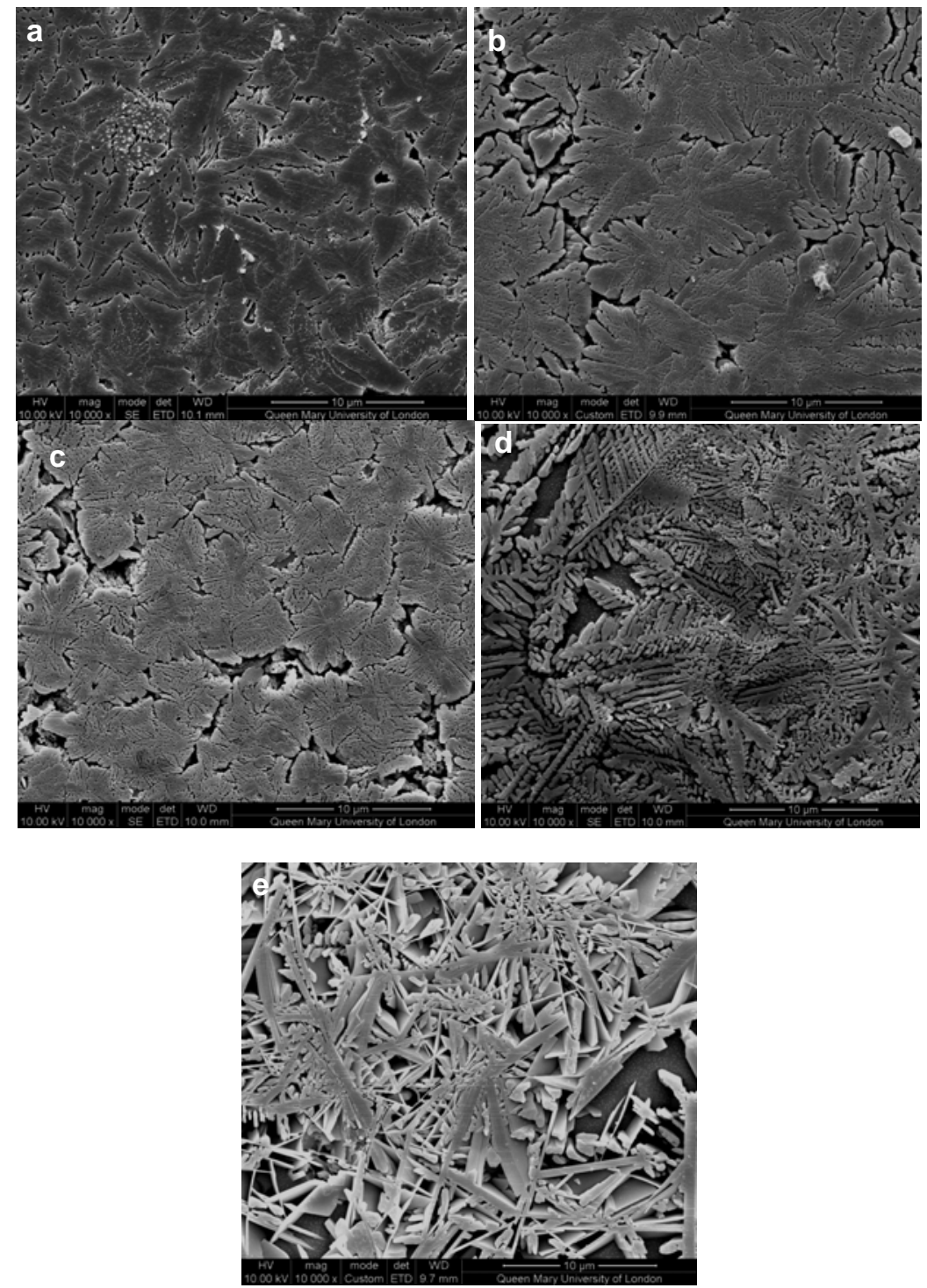

Fig 3: SEI photomicrograph of experimental glass-ceramics (a):100Di-0Jd, (b): 85Di-15Jd, (c): 75Di-25Jd, (d) 50Di-50Jd and (e): 25Di-75Jd.

\section{Conclusion.}

New diopside glass-ceramic with unique microstructures and TECs compatible with Y-TZP ceramics were successfully produced. These glass-ceramics can be useful as a veneering material for Y-TZP ceramics and for all-ceramic diopside restorations. The produced glass-ceramics might also be a potential candidate for bone replacement. 


\section{References.}

[1] Koenig, V., Vanheusden, A. J., Le Goff, S. O. \& Mainjot, A. K. 2013. Clinical risk factors related to faluires with zirconia-based restorations: An up to 9-year retrospective study. Journal of Dentistry, 41, 1164-1174.

[2] Aboushelib, M. N., De Jager, N., Kleverlaan, C. J. \& Feilzer, A. J. 2005. Microtensile bond strength of different components of core veneered all-ceramic restorations. Dental Materials, 21, 984-991.

[3] Rogers, P. 1970. The Initiation of Crystal Growth in Glasses. Mineralogical Magazine, 37, 741758.

[4] Abo-Mosallam, H., Hill, R., Karpukhina, N. \& Law, R. 2009. MAS-NMR studies of glasses and glass-ceramics based on a clinopyroxene-fluorapatite system. J. Mater. Chem., 20, 790-797.

[5] Nonami, T. \& Tsutsumi, S. 1999. Study of diopside ceramics for biomaterials. Journal of Materials Science: Materials in Medicine, 10, 475-479.

[6] Yoganand, C., Selvarajan, V., Lusvarghi, L., Goudouri, O., Paraskevopoulos, K. \& Rouabhia, M. 2009. Bioactivity of $\mathrm{CaO}-\mathrm{MgO}-\mathrm{SiO}_{2}$ glass ceramics synthesized using transferred arc plasma (TAP) process. Materials Science and Engineering: C, 29, 1759-1764.

[7] Miake, Y., Yanagisawa, T., Yajima, Y., Noma, H., Yasui, N. \& Nonami, T. 1995. Highresolution and analytical electron microscopic studies of new crystals induced by a bioactive ceramic (diopside). Journal of dental research, 74, 1756-1763.

[8] Nonami, T., Tsutsumi, S., Fukuma, M. \& Urabe, T. 1983. Press-formable CaO-SiO $2-\mathrm{MgO}$ glass ceramics for dental crowns. International Congress on Dental Material p.309.

[9] Jindal, R., Jayaganthan, R., Singh, I. V. \& Conradt, R. 2011. Synthesis and characterization of clinopyroxene based glasses and glass-ceramics along diopside $\left(\mathrm{CaMgSi}_{2} \mathrm{O}_{6}\right)$-jadeite $\left(\mathrm{NaAlSi}_{2} \mathrm{O}_{6}\right)$ join. ceramics International, 37, 741-748.

[10] Neuville, D. R., \& Mysen, B. O. (1996). Role of aluminium in the silicate network: In situ, high-temperature study of glasses and melts on the join $\mathrm{SiO}_{2}-\mathrm{NaAlO}_{2}$. Geochimica et Cosmochimica Acta, 60(10), 1727-1737.

[11] Kohn, S. C., Dupree, R., Mortuza, M. G., \& Henderson, C. M. B. (1991). NMR evidence for five-and six-coordinated aluminum fluoride complexes in F-bearing aluminosilicate glasses. American Mineralogist, 76(1-2), 309-312.

[12] De Jong, B. H. W. S., Schramm, C. M., \& Parziale, V. E. (1986). Geochim.Cosmochim.Acta, (47), 1223-1236.

[13] Otto, K., Wisniewski, W., \& Rüssel, C. (2013). Growth mechanisms of surface crystallized diopside. CrystEngComm, 15(32), 6381-6388. 
[14] Öveçoğlu, M. L., Kuban, B., \& Özer, H. (1997). Characterization and crystallization kinetics of a diopside-based glass-ceramic developed from glass industry raw materials. Journal of the European Ceramic Society, 17(7), 957-962. 